\title{
Fatores condicionantes de sucesso e/ou mortalidade de micro e pequenas empresas em Santa Catarina
}

\author{
Mariana Grapeggiaa,*, Alvaro Guillermo Rojas Lezana ${ }^{\mathrm{b}}$, \\ Anacleto Ângelo Ortigarac ${ }^{c}$, Paulo da Cruz Freire dos Santos ${ }^{\mathrm{d}}$ \\ a,*mgrapeggia@hotmail.com, SEBRAE, Brasil \\ blezana@deps.ufsc.br, UFSC, Brasil \\ canacleto@sc.sebrae.com.br, UNOESC,Brasil \\ dpaulodacruz@feac.ufal.br, UFAL, Brasil
}

\begin{abstract}
Resumo
0 objetivo deste artigo é descrever quais são os fatores que condicionam o sucesso e/ou a mortalidade das micro e pequenas empresas no Estado de Santa Catarina. Para a obtenção dos dados foi realizado um estudo de campo com uma amostra de empresas registradas na Junta Comercial do Estado nos anos de 2000 a 2004. Os dados foram analisados de forma qualitativa e quantitativa sob duas perspectivas: i) fatores relevantes na história do empreendimento (real), cujas maiores médias, na pontuação dada pelos empreendedores entrevistados, foram verificadas em conhecimento do produto/mercado, foco no negócio, identificação de oportunidades, organização e adequação dos produtos; e ii) fatores que o empreendedor acredita serem os mais importantes para o sucesso (ideal), cujas maiores médias ocorreram em organização, relacionamento entre os sócios, conhecimento do mercado, foco no negócio e identificação de oportunidades.
\end{abstract}

Palavras-chave

Sucesso. Fracasso. Fatores condicionantes. Micro e pequenas empresas.

\section{Introdução}

As micro e pequenas empresas (MPE) têm participação marcante na economia brasileira. Esta afirmação decorre dos números apresentados por pesquisas realizadas, como é o caso da publicação do Instituto Brasileiro de Geografia e Estatística - IBGE (2007), em que a distribuição do número de firmas, por faixas de pessoal ocupado, mostra que a participação das empresas com até 4 pessoas ocupadas respondia por 83\% do total, e somada à participação daquelas com 5 a 19 empregados, este percentual passava a representar 96,9\%.

Conforme dados da Relação Anual de Informações Sociais - RAIS (2006 apud CALOÊTE, 2009), entre 2003 e 2006 a participação das MPE no total de empresas nacionais manteve-se no patamar de 99\%. Das 6,72 milhões de empresas formalmente registradas em 2006, 94,1\% (6,32 milhões) eram microempresas e 4,9\% (332,2 mil) pequenas empresas.
Pesquisa publicada pelo Serviço Brasileiro de Apoio às Micro e Pequenas Empresas - SEBRAE (2004), no ano em que teve início a pesquisa do estudo apresentado neste artigo, informa que a participação das MPE brasileiras na geração de empregos tem aumentado ano a ano. 0 número desses empreendimentos somava, em 2003, 5,5 milhões de estabelecimentos industriais, comerciais e de serviços, os quais respondiam por 20\% do Produto Interno Bruto, 12\% das exportações e $43 \%$ da renda total. Representavam, portanto, 60\% dos empregos, ou seja, 60 milhões de brasileiros e, destes, 24,1\% tinham carteira assinada (aproximadamente 14,5 milhões de trabalhadores).

Por outro lado, segundo dados da pesquisa Global Entrepreneurship Monitor - GEM, a motivação para empreender pode ser classificada por oportunidade, quando motivados pela percepção do nicho de mercado potencial, ou necessidade, quando 
motivados pela falta de alternativa satisfatória de trabalho e renda (GRECO et al., 2009).

Segundo Greco et al. (2009), no Brasil as taxas de empreendedores iniciais por necessidade flutuaram bastante no período 2001-2008, tendo atingido seu ápice em 2002 e maior queda em 2008, conforme dados a seguir: 2001 (5,7\%), 2002 (7,5\%), 2003 (5,5\%), 2004 (6,2\%), 2005 (5,3\%), $2006(5,6 \%), 2007(5,3 \%)$ e $2008(4,0 \%)$. As taxas de empreendedores iniciais por oportunidade também flutuaram no período 2001-2008, porém os números de 2001 e 2008 apresentam menor variação, conforme dados a seguir: $2001(8,5)$, $2002(5,8), 2003(6,9), 2004(7,0), 2005(6,0)$, $2006(6,0), 2007(7,2)$ e $2008(8,0)$. Tanto as taxas de empreendedores por necessidade quanto por oportunidade caíram no período 2001-2008 (GRECO et al., 2009).

De acordo com os resultados da pesquisa referida no parágrafo anterior (GRECO et al., 2009), no Brasil a razão entre empreendimento por oportunidade e necessidade é de 2,03, o que significa que estudos sobre empreendedorismo com o componente econômico têm maior relação com a população de empresários de micro e pequenas empresas.

Esses números, no entanto, não podem ser vistos apenas sob uma óptica positiva, especificamente nos estados da região Sul, onde o índice de mortalidade (com base no período 2000 a 2002) é de 52,9\% para empresas com até dois anos de existência; para empresas com até três anos é de 60,1, e 58,9\% para empresas com até quatro anos, o que evidencia um ciclo de vida muito curto (SEBRAE, 2004).

Por meio de consulta a empresários e consultores, o Sebrae tem realizado pesquisas em anos sucessivos, focadas na identificação dos fatores que colaboram para a mortalidade das empresas brasileiras. 0 foco de tais pesquisas difere do apresentado no presente estudo, porém serve como referencial que sustenta pressupostos que permitem chegar aos verdadeiros fatores, indo além dos sintomas de mortalidade.

0 tratamento inadequado e a falta de abrangência das pesquisas deixam uma lacuna que, todavia, pode ser reparada a partir de um estudo científico e acadêmico. Dentro desse escopo, é sabido que micro e pequenas empresas apresentam ciclo de vida de curta duração, com enunciados que apontam questões que não escapam ao limite de sintomas. Nesse caso, cabe a seguinte pergunta de pesquisa: quais são os fatores condicionantes do sucesso e/ou mortalidade das micro e pequenas empresas no Estado de Santa Catarina?

0 objetivo deste artigo é descrever a pesquisa e apresentar os resultados de um estudo para identificação dos fatores condicionantes do sucesso e/ou mortalidade, nos primeiros anos de existência, das MPE do Estado de Santa Catarina.

Convém assinalar que embora a mortalidade de empresas seja quase sempre associada ao fracasso do empreendedor, muitas vezes ocorre que este decide fechar o empreendimento para iniciar outro, que na sua visão é mais vantajoso, ou, então, repassa a empresa para um terceiro.

\subsection{Justificativa}

Em 2005 foi desencadeada ampla discussão no Brasil sobre o tema deste estudo, que resultou na regulamentação da Lei Geral das MPE, cujo propósito era estabelecer e regulamentar incentivos para tais empresas, de forma a promover um sistema mais simples e justo de pagamento de impostos e contribuições, crédito facilitado, redução da burocracia e maior acesso às compras governamentais, às exportações e às novas tecnologias. 0 interesse pela aprovação de uma lei geral fundamentou-se na participação das MPE na sociedade brasileira.

A GEM (SCHLEMM et al., 2007), em sua pesquisa sobre as diferentes naturezas do empreendedorismo, se por oportunidade ou por necessidade, ressaltava que no Brasil a cada um empreendedor por oportunidade havia um por necessidade, um número considerado alarmante quando comparado aos países desenvolvidos, cuja proporção é de nove para um. Segundo o estudo, os motivos geradores desses números decorrem dos diversos problemas sociais vivenciados pelo país, a exemplo do desemprego, da educação, da saúde, da economia, dentre outros. Essas instabilidades agravadas pelas dificuldades de inserção no mercado de trabalho resultaram na busca por novas alternativa de subsistência. 0 fato, talvez, de as condições sociais terem melhorado justifica a redução na taxa de empreendedorismo por necessidade na pesquisa publicada em 2009.

Do ponto de vista conceitual, os empreendimentos baseados em nichos de mercado devem ter uma vida maior do que aqueles destinados a cobrir necessidades imediatas.

De acordo com os dados do IBGE (INSTITUTO..., 2007), somente $38,2 \%$ das MPE conseguem manter-se em atividade até o quinto ano de sua existência - 61,8\% delas são fechadas antes de completar esse prazo. Atente-se ao fato de que tais empresas desempenham importante papel como geradoras de empregos e proporcionam consequente desenvolvimento social nas regiões em que se encontram.

Com relação à geração de emprego, os dados da Relação Anual de Informações Sociais (BRASIL, 
2004) mostram que, no Brasil, as micro e pequenas empresas formais respondiam por $41,4 \%$ dos postos de trabalho, as médias por $12,3 \%$ e as grandes por 46,3\%. Especificamente por porte e setor de atividade, esse relatório mostra que, na indústria (trabalho formal), 51\% são MPE, 26\% são médias empresas e 23\%, grandes. No setor comércio (trabalho formal), tem-se: MPE 9\%, médias 78\% e grandes 13\%. No setor serviços (trabalho formal), 26\% são MPE, 6\% são médias e 68\% grandes.

0 estudo realizado e aqui descrito insere-se no contexto de integração com as políticas de desenvolvimento regional, sua orientação estratégica associada a uma abordagem da base para o topo, e pelo conhecimento dos fatores que condicionam a mortalidade precoce de empresas. Nesse sentido, Moreira (2005) realizou um estudo que aponta para a importância do tratamento dispensado às MPE no crescimento econômico com desenvolvimento social, pois elas contribuem para:

- 0 aumento dos recursos;

- A promoção da inclusão social;

- A possibilidade de desconcentração de renda;

- A ampliação das oportunidades aos setores pouco intensivos de capital e tecnologia e intensivos em mão de obra, insumos e matérias-primas locais;

- A causa de menos impactos ambientais, culturais e socioeconômicos;

- A formação de empreendedores, executivos e lideranças empresariais e sociais.

Sob o aspecto acadêmico, a pesquisa aqui relatada acresce aos estudos já realizados a proposta de buscar as razões da mortalidade empresarial nas fases da gênese e da operação propriamente dita. Evidencia-se, desse modo, um olhar diferente para a questão, uma vez que se consideraram as características do nascimento da organização até o desenvolvimento das atividades. Portanto, os resultados podem contribuir para a geração de novos estudos específicos para os fatores levantados e a elaboração de novos instrumentos de apoio aos empreendedores.

\section{Referencial teórico}

0 referencial teórico aqui exposto caracteriza as micro e pequenas empresas e apresenta estudos que apontam os possíveis fatores de sucesso/fracasso, sob a óptica da gênese e da operação do negócio, aspectos que fundamentam esses estudos.

\subsection{Micro e pequenas empresas}

No Brasil as MPE são definidas pelo Simples (Sistema Integrado de Pagamentos de Impostos e Contribuições das Microempresas e Empresas de Pequeno Porte - conforme Lei no 9.317/96) e pelo Estatuto da Microempresa e Empresa de
Pequeno Porte (Lei no 9.841/99). Nessa lei, no Decreto $n^{\circ}$ 5.028, de 31 de março de 2004, as MPE são classificadas de acordo com a receita bruta anual, da seguinte forma: microempresa é aquela constituída por pessoa jurídica ou firma mercantil individual que tiver receita bruta anual igual ou inferior a $\mathrm{R} \$ 433.755,14$; e empresa de pequeno porte é aquela que tiver receita bruta anual superior a $\mathrm{R} \$ 433.755,14$ e igual ou inferior a R\$ 2.133.222,00.

Há ainda uma classificação pelo número de empregados, utilizada pelo Sebrae, e a RAIS/TEM (Relação Anual de Informações Sociais / Ministério do Trabalho e Emprego) do governo federal, segundo a qual se considera microempresa aquela indústria que tem até 19 empregados e, no segmento de comércio/serviço, a que tem até 9 empregados. Já pequena empresa, na indústria, caracteriza-se por ter de 20 a 99 empregados e, no comércio/ serviço, de 10 a 49 empregados. A média empresa, na indústria, tem de 100 a 499 empregados e, no comércio/serviço, de 50 a 99 empregados. Uma grande empresa, na indústria, tem mais de 499 empregados e, no comércio/serviço, mais de 99 empregados.

Segundo o IBGE (INSTITUTO..., 2003), as MPE se caracterizam por: baixa intensidade de capital, altas taxas de natalidade e de mortalidade, forte presença de proprietários e/ou sócios dos negócios, centralização de poder, dificuldade de acesso a crédito, confusão entre pessoa física e jurídica, registros contábeis pouco adequados, contratação direta de mão de obra, utilização de mão de obra não qualificada ou pouco qualificada, baixo investimento em inovação tecnológica, relação de complementaridade e subordinação com as empresas de grande porte.

Para apresentar o conceito das MPE, tradicionalmente, são utilizados vários parâmetros, entre eles: mão de obra empregada, capital investido, faturamento, quantidade produzida etc. Neste estudo considerou-se faturamento e quantidade de empregados.

\subsection{Fatores condicionantes do sucesso/ fracasso das MPE}

0 sucesso ou o fracasso de empresas de pequeno porte tem-se constituído em preocupação nos meios político, acadêmico e empresarial, calcado nos altos índices de mortalidade empresarial. Para apontar os fatores referentes à sobrevivência de uma nova empresa, autores como Lezana e Tonelli (1998) fundamentaram seus estudos em três grupos: características individuais do fundador; características estruturais e estratégicas do novo negócio; e condições determinadas pelo meio ambiente da empresa. 
Consideram-se as duas primeiras fases do ciclo de vida de um empreendimento. A primeira refere-se à concepção da ideia, induzida pelo desejo do empreendedor de iniciar uma nova empresa, planejar, escolher a formação societária e aceitar as motivações para o negócio. A segunda fase caracteriza-se pelo início da operação e os primeiros anos de vida, nos quais o empreendedor responde por tomadas de decisões associadas ao funcionamento da empresa.

A sintese da pesquisa documental deste estudo, representada na Figura 1, mostra numa primeira categoria os fatoresrelacionadosà gênese do negócio: características do empreendedor, planejamento do negócio, composição societária e motivação para iniciar o empreendimento. Numa segunda categoria encontram-se as causas localizadas na operação da organização, determinadas pelo ambiente interno e pelo ambiente externo.

Os itens a seguir descrevem com mais detalhes, com base na pesquisa bibliográfica, os elementos do constructo apresentados na Figura 1.

\subsubsection{Fatores condicionantes do sucesso/ fracasso das MPE com foco na gênese}

Especificamente em relação à gênese do negócio, esse tópico apresenta considerações de estudos anteriores relacionados aos fatores de sucesso apontados em diversos estudos relacionados à gênese do empreendimento.

Do ponto de vista do empreendedorismo, observa-se que desde o século XVIIl alguns economistas têm-se interessado por compreender melhor o papel do empreendedor como o motor do sistema econômico (CANTILLON, 1755; SCHUMPETER, 1961; STEL; CARREE; THURIK, 2005). De acordo com Brollo (2005), ao longo da história, o empreendedor foi estudado como um criador de empresas, tomador de riscos e como pessoa com alto nível de tolerância para trabalhar em condições de ambiguidade e incerteza. Para Longenecker, Moore e Petty (2004), a atitude de assumir risco moderado denota a outra característica do empreendedor, a autoconfiança. Já Scott e Bruce

\begin{tabular}{|c|c|c|c|}
\hline \multicolumn{4}{|c|}{ Gênese } \\
\hline Empreendedor & Planejamento & Sociedade & Motivação \\
\hline \multicolumn{4}{|c|}{ Fatores condicionantes de sucesso/fracasso } \\
\hline Internas & & & Externas \\
\hline \multicolumn{4}{|c|}{ Operações } \\
\hline
\end{tabular}

Figura 1. Constructo da origem dos fatores condicionantes de sucesso/fracasso das MPE. Fonte: Ortigara (2006).
(1987), descreveram o empreendedor como uma pessoa cujas decisões determinam diretamente o destino da empresa, quer essa pessoa assuma todo o controle ou todo o risco. Por outro lado, para Lezana e Tonelli (1998), os fatores característicos do empreendedor que o fazem intervir no processo de criação e desenvolvimento das empresas são suas necessidades, seus conhecimentos, suas habilidades e seus valores. Principalmente nos primeiros anos de vida a empresa será o reflexo do empreendedor.

A segunda consideração refere-se ao planejamento inicial do negócio, que se relaciona com a preparação para o início das atividades. Planejar implica em sair para o mundo e se questionar sobre a relevância dos fatores para 0 futuro do empreendimento. Para agir de modo preventivo, com presciência, a empresa deverá agir antecipadamente em função dos sinais emitidos pelo mercado, e não em reação às mudanças. Esse é um processo extremamente importante em todos os estágios de um empreendimento, sobretudo no início. À medida que o empreendimento evolui de uma nova empresa para uma empresa madura, o planejamento continuará e a administração buscará atingir suas metas de curto e longo prazo (HISRICH; PETERS, 2004). Novos negócios podem surgir sem planejamento formal, no entanto, a ideia existe na mente do empreendedor, que por algum tipo de motivação passa a investigar como transformá-la em empreendimento.

A terceira consideração diz respeito aos fatores relacionados à composição societária e ao relacionamento entre os sócios. Um dos dilemas que acompanham o empreendedor na fase inicial do seu negócio é a decisão por iniciar como único proprietário ou buscar um ou vários sócios. De acordo com Shane, Locke e Collins (2003), para iniciar uma nova empresa, em algumas situações, o empreendedor depara-se com a impossibilidade de realizar sozinho tal tarefa, ora por falta de capital, ora por falta de conhecimento e de habilidades. Dessa forma, uma composição societária é a alternativa decorrente.

É possível descobrir, ao analisar a história das organizações de qualquer porte, que muitas vezes a origem da nova empresa deu-se pela união de pessoas que se conheciam direta ou indiretamente, em maior ou menor grau.

A motivação é a quarta consideração. É sempre a motivação pessoal que move o empreendedor a iniciar um negócio, seja por necessidade ou por ter vislumbrado uma oportunidade. A necessidade pode estar relacionada aos seguintes motivos: aprovação, independência, desenvolvimento pessoal, segurança ou autorrealização (LEZANA; TONELLl, 2004). 
Alguns pesquisadores, dentre os quais se destacam Almquist e Angust (1971), Smake e Granger (1978), Carsrud, Gaglio e Kenneth (1987) e Aldrich e Zimmer (1987), atribuem a fatores motivacionais o desempenho de um empreendedor, de forma a influenciar sua carreira e, consequentemente, suas decisões. Essas motivações originam-se de modelos de desempenho individuais (pais do empreendedor, irmãos, parentes ou outros empreendedores) que servem de mentores. Shane, Locke e Collins (2003) defendem o estudo da motivação empreendedora, por considerar que ela influencia o desempenho financeiro de empresas novas. Por outro lado, perder tempo e dinheiro e a possibilidade de fracasso são fatores que desmotivam as pessoas. Nesse sentido, a presente pesquisa abordou os fatores positivos e negativos da gênese de um empreendimento.

\subsubsection{Fatores condicionantes do sucesso/ fracasso das MPE com foco na operação}

Nesse tópico, abordam-se, inicialmente, os fatores internos da organização, que são aqueles sobre os quais o empreendedor tem domínio. Posteriormente, são tratados os fatores externos ao negócio, determinados pelo ambiente no qual a empresa opera e que fogem do controle do empreendedor, fazendo-o reagir a eles.

Com referência aos fatores internos da empresa é possível dizer-se que, de acordo com Lezana e Tonelli (2004), eles intervêm diretamente no seu funcionamento e podem ser modificados pelos decisores. Os autores agrupam esses fatores a partir de subsistemas empresariais clássicos: direção e gestão; produção; pessoas; finanças; e comercial.

Dentre as inquietações para gerir o novo empreendimento, na direção e gestão, as primeiras habilidades que os empreendedores devem desenvolver referem-se às formas de organização, direção, planejamento e controles empresariais. 0 segundo subsistema diz respeito aos sistemas de produção, tecnologia, qualidade, fornecedores, engenharia, projeto de produtos e processos, gama de produtos etc. Qualificar a mão de obra, estabelecer sistemas de remuneração, recrutamento e seleção e sistemas de formação internos relacionam-se ao subsistema pessoas. As finanças compreendem aspectos associados à origem dos recursos, aos sistemas administrativos e controles financeiros. Finalmente, há o subsistema comercial, que se referem às formas de comercialização, determinação de preços, distribuição, assistência técnica, estudos de mercado, exportações etc.

Segundo Birley e Muzyka (2001), outra dificuldade apontada é a ausência de planejamento de longo prazo do espaço físico disponível para suportar aumentos de produção. No que diz respeito às pessoas, os autores consideram que o empreendedor pode enfrentar as seguintes dificuldades: compor e manter uma equipe administrativa, devido à falta de qualificação e falta de dinheiro para pagar os profissionais já treinados; gerenciar pessoas; manter comunicação constante com parceiros e investidores.

Quanto aos fatores externos, para Ansoff (1989) eles dizem respeito às oportunidades de produtos e mercados disponíveis à empresa fora de seu conjunto corrente de produtos, envolve as oportunidades e as ameaças ao empreendimento. Shane, locke e Collins (2003) dizem que o empreendedorismo não é somente o resultado de ação humana, pois fatores externos podem influenciar os fatores operacionais internos da organização, determinando a permanência ou não da empresa na atividade. Os fatores considerados são os seguintes: políticos (restrições legais, estabilidade política e estabilidade de moeda corrente); forças de mercado (estrutura organizacional, tecnologia, barreiras de entrada, tamanho de mercado e população demográfica); recursos (disponibilidade de capital investido, mercado de trabalho, infraestrutura de transporte e tecnologia complementar).

Oliveira (2005) cita o mercado, o governo, a tecnologia, o sistema financeiro, os sindicatos, a comunidade, os consumidores, os concorrentes e fornecedores como fatores externos que fogem ao controle da empresa. Nesse sentido, Lezana e Tonelli (2004) também afirmam que eles afetam o funcionamento de uma empresa e fogem ao controle do empreendedor.

Por outro prisma, Batista (2003) considera neste grupo o ambiente externo determinado pelas cinco forças do modelo de análise da competitividade empresarial de Michael Porter: fornecedores, clientes, entrantes, concorrentes e substitutos. 0 que ameaça o ambiente, sob a óptica de clientes e fornecedores, envolve: carteira de produtos, disponibilidade de substitutos, diferenciação ou custos de troca, ameaças de integração, contribuição para a qualidade dos serviços e produtos e lucratividade.

\section{Procedimentos metodológicos}

Do ponto de vista da abrangência, esta pesquisa foi realizada em todas as regiões do estado de Santa Catarina, num estudo de campo que possibilitou ampla observação e avaliação das características dos empreendedores locais.

A pesquisa que deu origem a este artigo teve caráter exploratório e coletou dados primários e secundários. Para a coleta de dados primários foi 
utilizada uma amostra aleatória, escolhida dentro dos três setores de atividade econômica: indústria, comércio e serviços.

Depois de definida a estrutura metodológica, a pesquisa foi realizada em sete etapas. Na primeira etapa, por meio de uma pesquisa bibliográfica, levantaram-se os prováveis fatores de sucesso/ fracasso das MPE, ao final da qual foram escolhidos os quesitos considerados relevantes para o sucesso/ fracasso de uma empresa, com relação à gênese do negócio (empreendedor, planejamento, sociedade, motivação) e aos fatores operacionais internos e externos, que deu origem à modelagem inicial.

Um grupo de especialistas em empreendedorismo e gestão de negócios foi selecionado para avaliar, em um workshop, os quesitos levantados na primeira etapa da pesquisa, que resultou na sua modelagem definitiva. Este trabalho permitiu incorporar aos quesitos iniciais alguns aspectos empíricos. Deste trabalho com o grupo de especialistas, foram definidos os itens para compor o instrumento de coleta de dados. A escolha foi realizada mediante a valoração destes, de mais para menos importante (atribuindo nota entre 1 e 10), com o objetivo de serem avaliados estatisticamente através de suas médias e desvios padrões. Assim, um quesito com média alta e baixa variabilidade foi indicativo de que os especialistas (analistas) o consideravam como importante para a análise do problema.

$\mathrm{Na}$ terceira etapa foram construídos os instrumentos de pesquisa, baseados nos elementos definidos nas etapas anteriores. Esses instrumentos correspondem a um questionário a ser aplicado para as empresas em atividade e outro para as extintas, ambos mediante o agendamento prévio com os empreendedores. Os questionários utilizados foram compostos por perguntas fechadas - com o uso de escala tipo likert de sete pontos, indo de 1 (irrelevante) a 7 (muito importante) -, direcionadas a identificar fatores de sucesso/fracasso dos empreendimentos além de obter informações sobre a gênese e a operação do negócio. A Figura 2, a seguir, resume as etapas da pesquisa.

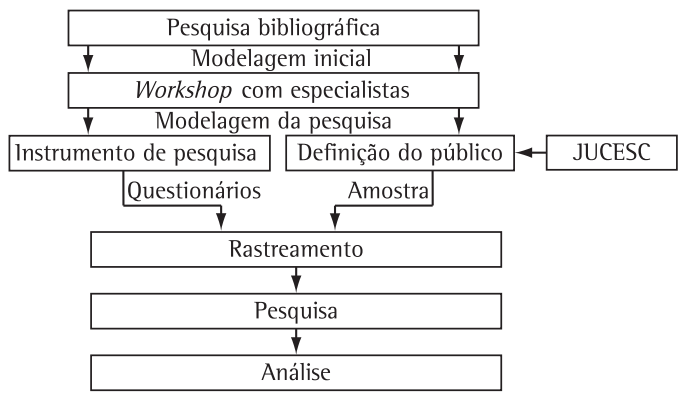

Figura 2. Etapas da pesquisa.
Nos questionários foram consideradas duas situações: a primeira sob a óptica do que o empreendedor considera ideal para o sucesso do seu negócio e a segunda relacionada à perspectiva real, ou seja, o que fez, ou não, a diferença no início do negócio e em sua gestão. Esse contraste entre o idealizado e o realizado visou indicar, na opinião dos entrevistados, os fatores mais relevantes para o sucesso e para o fracasso do empreendimento.

Esses instrumentos foram testados e avaliados com empreendedores de micro e pequenas empresas da região da grande Florianópolis, até a obtensão da versão definitiva. Paralelamente, houve a seleção da amostra, resultante da etapa de definição do público ou população pesquisada (quarta), com base no número de empresas registradas na Junta Comercial do Estado de Santa Catarina - JUCESC, conforme Tabela 1. Ou seja, o plano amostral da pesquisa partiu de um universo de 119.083 empresas registradas na JUCESC, entre os anos de 2000 e 2004, escolhidas por meio de processo aleatório, considerando-se um intervalo de confiança de 95\% e uma margem de erro de 5 pontos percentuais para mais e para menos.

Para a estratificação da amostra se consideraram, além do universo da população, sua distribuição geográfica (oeste, planalto serrano, norte, vale do Itajaí, sul e grande Florianópolis), o ano de registro e a categoria (empresa ativa ou extinta).

Uma das grandes dificuldades na realização de pesquisa desta natureza é a localização dos empreendedores a serem entrevistados, principalmente pela desatualização dos dados da JUCESC e pelo baixo percentual de empresas que solicitam a baixa de seu registro quando encerram suas atividades. Por esta razão, a quinta etapa consistiu no rastreamento dos empresários da amostra, com vistas a localizá-los. Para tal foram realizadas pesquisas aos telefones das empresas e dos sócios, conforme registro na Junta Comercial, além de consultas a diferentes serviços de auxílio à lista (Brasil Telecom, Telelistas, GVT, Telefônica, Lista On-line), pesquisas na internet, visitas in loco e sondagens aos vizinhos.

$\mathrm{Na}$ sexta etapa o questionário foi aplicado, presencialmente, por pesquisadores treinados para tal fim a empreendedores de micro e pequenas empresas, conforme se apresenta na Tabela 2.

Tabela 1. Número de empresas registradas na JUCESC.

\begin{tabular}{cc}
\hline Ano & Empresas registradas \\
\hline 2000 & 24.097 \\
2001 & 25.583 \\
2002 & 23.550 \\
2003 & 22.529 \\
2004 & 23.324 \\
\hline
\end{tabular}

Fonte: dados da pesquisa. 
Tabela 2. Mapa de entrevistas realizadas.

\begin{tabular}{cccccc}
\hline Região & Amostra & $\begin{array}{c}\text { Entrevistas } \\
\text { realizadas } \\
\text { (empresas ativas) }\end{array}$ & $\begin{array}{c}\text { Entrevistas realizadas } \\
\text { (empresas extintas) }\end{array}$ & $\begin{array}{c}\text { Número de empresas } \\
\text { não localizadas/ } \\
\text { recusadas }\end{array}$ & $\begin{array}{c}\text { Percentual } \\
\text { da amostra } \\
\text { realizado (\%) }\end{array}$ \\
\hline Oeste & 203 & 70 & 05 & 128 & 34,00 \\
Planalto serrano & 106 & 24 & 07 & 75 & 24,00 \\
Norte & 254 & 71 & 05 & 178 & 28,00 \\
Vale do ltajaí & 282 & 61 & 11 & 143 & 22,00 \\
Sul & 180 & 32 & 05 & 291 & 18,05 \\
Grande Florianópolis & 368 & 71 & 39 & 1025 & 19,30 \\
Total & 1393 & 329 & & & 24,10 \\
\hline
\end{tabular}

Fonte: dados da pesquisa.

A análise dos dados constituiu na última etapa da pesquisa, realizada por meio de tratamento estatístico das informações coletadas, com a utilização de técnicas de análise exploratória de dados, e o teste U de Mann-Whitney, que compara duas amostras (STEEL; TORRIE, 1988), para observar possiveis diferenças nas opiniões/expectativas dos grupos de empreendedores das empresas em atividade e extintas, o que permitiu identificar e descrever os resultados obtidos entre as empresas, tanto em atividade como as extintas, e realizar análises cruzadas dos resultados empresariais com os do perfil do empreendedor (porém neste artigo só se apresentam os resultados relacionados com os fatores de sucesso e fracasso observados na amostra). Esse teste foi escolhido por ser uma alternativa não paramétrica para o teste $t$, e ainda por ser adequado quando as amostras envolvidas possuem tamanhos desiguais e são mensuradas no mínimo no nível ordinal, caso dos dados da pesquisa que gerou este artigo.

\section{Apresentação e análise dos resultados}

Apresentam-se, a seguir, os resultados da análise exploratória dos dados coletados junto aos empreendedores pesquisados, que compreendem perfil do empreendedor, dos emprendimentos e os fatores de fracasso.

\subsection{Descrição do perfil dos empreendedores entrevistados}

A população pesquisada apresentou as seguintes características:

- Predomínio de sócios-gerentes do sexo masculino $(68 \%)$;

- $58,7 \%$ dos empreendedores encontram-se na faixa de 30 a 49 anos;

- 43,48\% possuem terceiro grau completo e, dentre os empreendedores com empresas ativas, praticamente 30\% são pós-graduados;

- Nas empresas ativas, 55,83\% dos empreendedores exerciam antes da criação da empresa a atividade de funcionário público, ao passo que, nas extintas, 53,85\% trabalhavam em empresas privadas;

- 27,45\% dos entrevistados não tinham experiência anterior no ramo do negócio.

Os principais motivos para abertura do negócio, segundo os entrevistados, foram:

- Identificação de oportunidade (34\%);

- Desejo de ter um negócio próprio (25\%);

- Ocorrência simultânea dos dois motivos (11\%);

- Desejo de aumentar a renda e melhorar de vida (9\%).

0 restante $(21 \%)$ apontou motivos diversos, como: terceirização dos serviços, concessão, adequação a clientes ou legislação, ajustes de empresas familiares.

\subsection{Descrição do perfil dos empreendimentos}

Os resultados da pesquisa com empresas ativas e extintas apresentados nesta seção revelaram uma série de informações sobre o setor de atividade e porte da empresa. Entre as empresas entrevistadas houve concentração em dois setores da atividade econômica: comércio e serviços.

Os dados obtidos ainda mostraram que, quanto ao número total de empregados registrados no Ministério do Trabalho, mais de $76 \%$ das empresas em atividade empregavam de um a quatro trabalhadores. Por outro lado, nas empresas extintas, 100\% empregaram até três trabalhadores. A situação muda pouco quando se considera o número de trabalhadores sem carteira assinada. 0 número de funcionários não registrados no Ministério do Trabalho foi menor do que 20\%, tanto em empresas ativas como nas extintas.

\subsection{Fatores condicionantes do sucesso/fracasso}

Para as análises apresentadas a seguir, foram considerados os quesitos atribuídos aos fatores condicionantes de sucesso e fracasso de uma 
empresa conforme a opinião dos especialistas, no workshop. Conforme informado na metodologia, os empreendedores entrevistados foram indagados sobre os aspectos relacionados ao sucesso, considerados ideais, e aqueles que efetivamente praticaram (reais).

Para a situação considerada ideal, as médias das respostas com relação às expectativas existentes no início do negócio - sob a óptica dos entrevistados das empresas em atividade e extintas - possibilitaram listar a importância atribuída a cada um dos fatores. A Tabela 3, a seguir, apresenta os dez fatores com maiores escores (escala tipo Likert de 7 pontos).

Pode-se observar que há uma diferença entre as prioridades apontadas pelos empreendedores de empresas ativas e extintas. Isso poderia indicar que a preocupação dos empreendedores ativos com a gênese da empresa e os aspectos relacionados com seu funcionamento e produtos oferecidos se relacionariam com os fatores de sucesso. No entanto, empreendedores que fracassaram apontaram como prioridade problemas decorrentes da falta de habilidade para resolver conflitos e focar as atividades do negócio.

De acordo com as médias dos escores obtidos pelos resultados das entrevistas, pode-se observar, na Tabela 3, uma diferenciação na ordem dos fatores pesquisados quanto à hierarquização das prioridades pelo cálculo das médias. Entretanto, um teste (U de Mann-Whitney) comparando os escores dos grupos de empreendedores com empresas em atividade e extintas, por cada fator presente entre as duas condições, não mostrou diferenças significativas ( $p>0,05$ ). lsso indica que os fatores onde os dois grupos foram comparados não são determinantes para explicar o sucesso/fracasso dos seus integrantes e que, talvez, as razões sejam decorrentes também de outros fatores não estudados.

Isso pode ser um indício para que novos estudos sobre o assunto sejam levados a efeito.

Com relação aos fatores e aspectos internos associados à gestão, na perspectiva de uma situação ideal (Tabela 4), os três maiores valores médios das pontuações atribuídas pelos entrevistados de empresas ativas correspondem a: controle administrativo, adequação de produtos e conhecimento do mercado. Por outro lado, para as empresas extintas as três maiores médias são: conhecimento do mercado, controle administrativo e gestão do capital de giro.

A exemplo dos fatores apresentados na Tabela 3, não houve diferenças significativas entre os dois grupos ( $p>0,05)$, indicando que outras variáveis devem ser incluídas em estudos futuros sobre os fatores condicionantes do sucesso/fracasso empresarial.
Tabela 3. Valores médios observados das expectativas existentes no início do negócio, em uma situação ideal.

\begin{tabular}{ccc}
\hline Expectativas & $\begin{array}{c}\text { Em } \\
\text { atividade }\end{array}$ & Extintas \\
\hline Senso de organização* & 6,58 & 6,31 \\
Conhecimento do produto/mercado & 6,52 & - \\
Motivação por oportunidade & 6,41 & 6,29 \\
Relacionamento entre os sócios* & 6,36 & 6,47 \\
Definição do foco do negócio & 6,31 & 6,36 \\
Habilidade para lidar com & 6,26 & 6,13 \\
$\quad$ informações & 6,23 & 6,30 \\
Instrumentos de planejamento & 6,11 & 6,31 \\
Pessoa física/jurídica & 5,96 & 6,07 \\
Tomar decisões rápidas & 5,88 & 6,02 \\
Experiência em outras empresas & & 5,91 \\
Habilidade de perceber & - & \\
oportunidades & &
\end{tabular}

*Fator considerado pelos entrevistados como o mais importante.

Fonte: dados da pesquisa.

Tabela 4. Valores médios observados numa situação ideal para fatores internos associados à gestão.

\begin{tabular}{lcc}
\hline \multicolumn{1}{c}{ Discriminação } & \multicolumn{2}{c}{$\begin{array}{c}\text { Médias das pontuações } \\
\text { dos entrevistados }\end{array}$} \\
\cline { 2 - 3 } & $\begin{array}{c}\text { Empresas } \\
\text { em atividade }\end{array}$ & $\begin{array}{c}\text { Empresas } \\
\text { extintas }\end{array}$ \\
\hline Fatores internos & & \\
\hline lnstrumentos de controle & $* 6,60$ & 6,51 \\
$\begin{array}{l}\text { administrativo } \\
\text { Adequabilidade de produtos }\end{array}$ & 6,58 & 6,36 \\
e mix & & \\
Conhecimento do mercado & 6,58 & $* 6,63$ \\
Habilidade com situações & 6,52 & 6,30 \\
novas & 6,47 & 6,44 \\
$\quad$ Gestão do capital de giro & & \\
\hline Aspectos externos & $* 5,99$ & $* 5,88$ \\
\hline Acesso a financiamento & 5,89 & 5,67 \\
Oferta de insumos & 5,85 & 5,66 \\
Financiamento de compras & 5,50 & 5,77 \\
Financiamento de vendas & 5,33 & 5,14 \\
\hline Concorrência &
\end{tabular}

*Fator considerado pelos entrevistados como o mais importante.

Fonte: dados da pesquisa.

A Figura 3 apresenta um resumo dos fatores de sucesso/fracasso, na óptica dos entrevistados, que apresentaram pontuações médias mais altas tanto para a fase da gênese quanto da operação da nova organização, sob a perspectiva ideal.

Como os fatores de análise são os mesmos para empresas ativas e extintas, o destaque para a importância atribuída está representado de três formas: a primeira por uma mudança no tipo de borda das caixas de textos, sendo que a borda com linha contínua utilizada é para designar as preferências das empresas que não atuam mais no 


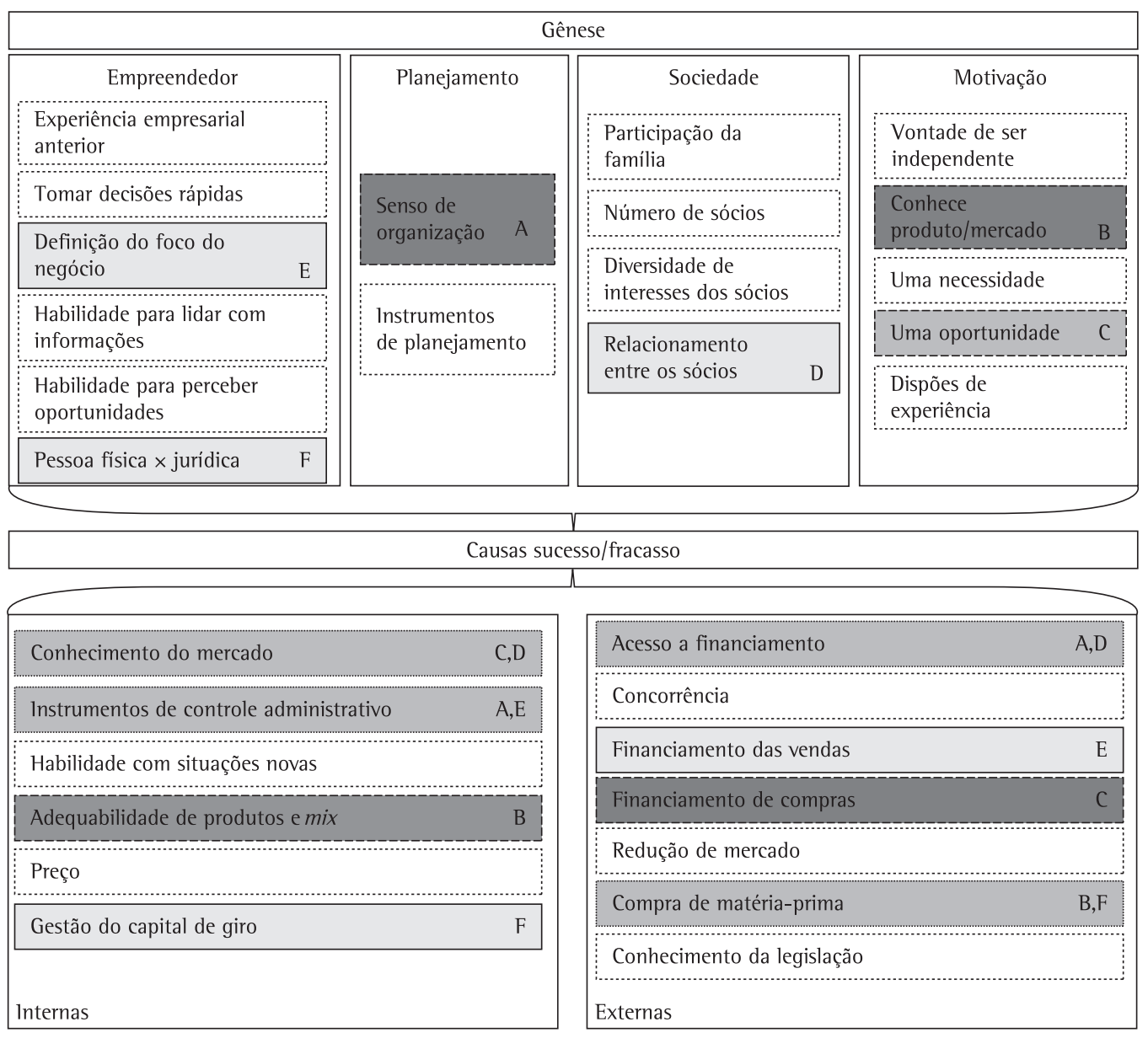

\section{Operação}

\section{D, E, F Preferências dos entrevistados de empresas extintas \\ I] A, B, C Preferências dos entrevistados de empresas ativas Preferências coincidentes entre os entrevistados}

Figura 3. Fatores condicionantes do sucesso/fracasso de acordo com a opinião dos entrevistados sob a perspectiva ideal.

mercado, e as bordas intermitentes para representar as preferências de empresas em atividade para a situação considerada ideal. A segunda diferenciação é pela cor do fundo da caixa de texto: o cinza-claro representa as empresas extintas, o escuro, as ativas, e a existência das duas cores indica que os entrevistados tanto de empresas ativas como extintas consideraram o fator importante. A terceira forma de destaque é pelo uso de letras, sendo que $\mathrm{A}, \mathrm{B}$ e $\mathrm{C}$ representam, na ordem, as maiores pontuações segundo preferência dos proprietários de empresas em atividade, e D, E, F as respostas dos proprietários das empresas extintas.

As diferenças nas preferências podem ser indício dos fatores de fracasso, pois os empreendedores que estão em atividade têm uma visão diferente daqueles que fracassaram. A Tabela 5 apresenta as dez maiores médias atribuídas pelos entrevistados, de empresas ativas ou não, aos fatores relacionados à gênese do empreendimento.

Ainda com base no resultado do teste $\mathrm{U}$ de Mann-Whitney, foi possível constatar diferenças significativas $(p<0,05)$ entre as variáveis: habilidade de perceber oportunidades, relacionamento com os sócios e habilidade para lidar com informações. As demais variáveis não se mostraram significativas ( $p>0,05)$.

De acordo com os entrevistados das empresas em atividade e das extintas, no início do empreendimento o fator "conhecimento do produto" é o mais importante para o sucesso. No entanto, o grau de importância dado pelas empresas em atividade para os sete primeiros itens da Tabela 5, com escores maiores que 5,7, é maior que todos os apontados 
Tabela 5. Valores médios observados em uma situação real, para as expectativas existentes no início do negócio.

\begin{tabular}{|c|c|c|}
\hline Expectativas & $\begin{array}{l}\text { Em } \\
\text { atividade }\end{array}$ & Extintas \\
\hline Conhecimento do produto/mercado* & 6,03 & 5,51 \\
\hline Definição do foco do negócio & 6,01 & 5,38 \\
\hline $\begin{array}{l}\text { Habilidade de perceber } \\
\text { oportunidades }\end{array}$ & 6,00 & 5,20 \\
\hline Senso de organização & 5,98 & 5,49 \\
\hline Vontade de ser independente & 5,92 & 5,38 \\
\hline Motivação por oportunidade & 5,84 & 5,50 \\
\hline Relacionamento entre os sócios & 5,72 & 4,78 \\
\hline $\begin{array}{l}\text { Habilidade para lidar com } \\
\text { informações }\end{array}$ & 5,45 & 4,57 \\
\hline Experiência em outras empresas & 5,29 & 4,39 \\
\hline Pessoa física/jurídica & 5,08 & 4,52 \\
\hline
\end{tabular}

*Fator considerado pelos entrevistados como o mais importante. Fonte: dados da pesquisa.

Tabela 6. Valores médios observados em uma situação real para fatores internos e externos à gestão da empresa.

\begin{tabular}{|c|c|c|c|}
\hline & Expectativas & $\begin{array}{l}\text { Em } \\
\text { atividade }\end{array}$ & Extintas \\
\hline \multirow{5}{*}{$\begin{array}{l}\text { Fatores } \\
\text { internos }\end{array}$} & $\begin{array}{l}\text { Adequação de } \\
\text { produtos e } m i x^{*}\end{array}$ & 6,27 & 5,44 \\
\hline & $\begin{array}{l}\text { Habilidade com } \\
\text { situações novas }\end{array}$ & 6,26 & 5,36 \\
\hline & $\begin{array}{l}\text { Conhecimento do } \\
\text { mercado }\end{array}$ & 6,15 & 5,42 \\
\hline & Preço & 5,88 & 5,14 \\
\hline & $\begin{array}{l}\text { Instrumentos de } \\
\text { controle administrativo }\end{array}$ & 5,87 & 4,94 \\
\hline \multirow{5}{*}{$\begin{array}{l}\text { Aspectos } \\
\text { externos }\end{array}$} & Oferta de insumos* & 5,54 & 4,77 \\
\hline & $\begin{array}{l}\text { Financiamento } \\
\text { de compras }\end{array}$ & 5,11 & 4,41 \\
\hline & $\begin{array}{l}\text { Redução de } \\
\text { mercado* }\end{array}$ & 5,11 & 5,42 \\
\hline & Concorrência & 4,96 & 4,77 \\
\hline & $\begin{array}{l}\text { Financiamento } \\
\text { de vendas }\end{array}$ & 4,85 & 4,60 \\
\hline
\end{tabular}

*Fator considerado pelos entrevistados como o mais importante. Fonte: dados da pesquisa.

pelas empresas extintas, cujos escores iniciam em 5,5. Isso mostra grande diferença de atitude dos empreendedores com relação ao seu negócio.

Chama atenção a pouca importância relativa à habilidade de perceber oportunidades, atribuída pelos empreendedores fracassados; essa constatação corrobora a opinião de diversos autores sobre a motivação e o desempenho do empreendedor. Esse resultado abre possibilidades para trabalhos que visem subsidiar empreendedores iniciantes.
A Tabela 6 apresenta as preferências dos entrevistados de empresas ativas e extintas sobre os fatores de sucesso internos e externos à organização.

Especificamente para as variáveis relacionadas aos fatores internos: adequação de produtos e mix, habilidade com situações novas, conhecimento do mercado, preço, instrumentos de controle administrativo; 0 teste $\mathrm{U}$ de Mann-Whitney mostrou significância (p $<0,05)$ indicando diferenças entre os dois grupos estudados. Já as habilidades relacionadas a fatores externos não apresentaram significância ( $p>0,05)$. Isso indica, portanto, que as variáveis que intervêm diretamente no funcionamento da empresa, e sobre as quais o empreendedor tem domínio, influenciam nos resultados da empresa no mercado.

As informações anteriores estão sintetizadas na Figura 4, em que se apresentam em destaque os fatores mais relevantes nas duas fases do negócio, sob a perspectiva real, ou seja, daquilo que os empreendedores efetivamente praticam ou praticaram.

Essa figura segue o mesmo padrão informacional da Figura 3, ou seja, cor cinza-claro e borda tipo linha representam as preferências dos entrevistados de empresas extintas, enquanto o destaque cinzaescuro e borda intermitente indicam as preferências dos entrevistados das empresas em atividade. Casos em que existem os dois tons de cinza mostram coincidências de opinião entre entrevistados de empresas ativas e extintas. As letras seguem o mesmo padrão estabelecido para a figura dos resultados sob a perspectiva ideal.

Observe que não há diferenças significativas nas preferências em relação aos fatores internos. No entanto, percebe-se uma diferença na ênfase dada aos fatores externos (valor das médias).

\section{Considerações finais}

Os resultados da pesquisa apontam que o modelo conceitual, gênese e operação, se mostrou adequado para levantar os possíveis fatores de mortalidade das empresas junto aos empresários. Ainda, permitem direcionar ações futuras com vistas a promover a redução da mortalidade empresarial. No entanto, é preciso ampliar a pesquisa para incorporar fatores derivados da evolução do empreendimento.

0 que se observa, do ponto de vista teórico, é que a percepção do empreendedor sobre o fenômeno do empreendedorismo relaciona-se diretamente com o sucesso do empreendimento. Por essa razão o modelo elaborado pode servir para estudos futuros sobre fatores de sucesso das empresas.

É importante ressaltar, também, que grande parcela dos fatores encontrados na pesquisa 


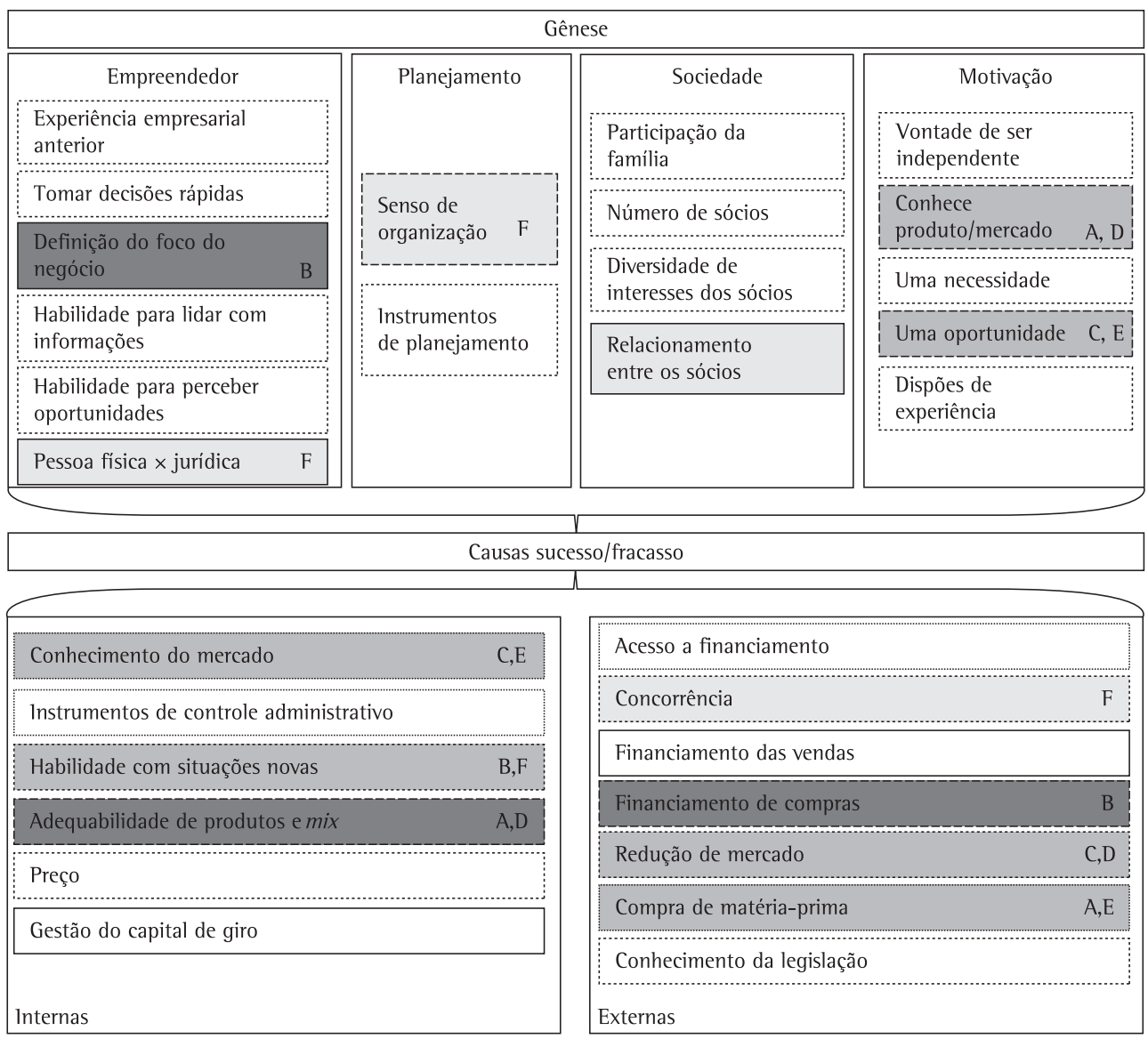

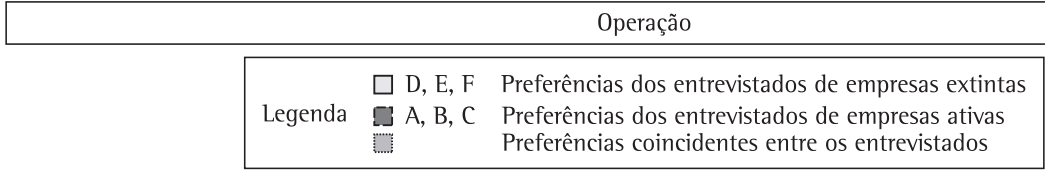

Figura 4. Fatores condicionantes do sucesso/fracasso segundo os entrevistados sob a perspectiva real.

corrobora boa parte das diferentes abordagens teóricas apresentadas na revisão dos trabalhos dos autores pesquisados.

0 problema e os objetivos deste artigo foram respondidos, pois a pesquisa realizada com empreendedores de micro e pequenos negócios possibilitou relacionar os fatores de sucesso de um empreendimento, entre os quais nota-se pequena divergência entre o ideal e o real. Nesse sentido, o fator relacionado ao planejameno foi considerado como ideal para o sucesso, porém os empresários de empresas ativas disseram que no início seu foco estava no negócio e no conhecimento sobre o mercado e não no planejamento.

A complexidade que cerca os fatores condicionantes ao sucesso e fracasso das empresas tem razões que continuam intrigando os pesquisadores.
A mortalidade de empresas é, muitas vezes, associada ao fracasso do empreendedor. Esquece-se, porém, que algumas vezes ele decide fechar o empreendimento para iniciar outro, que na sua visão é mais vantajoso, e repassa a empresa para um terceiro. Em situações como essa é inadequado falar em fracasso. Consequentemente, o fracasso está associado a variáveis endógenas ou exógenas, ou mesmo a uma conjunção de ambas.

Como uma das limitações da pesquisa pode-se citar o fato que ela utilizou um corte transversal da realidade das empresas catarinenses. Cortes transversais, quando levantam dados sobre situações que ocorreram em momentos distantes, correm o risco de obter informações distorcidas. Outra limitação é ter incluído somente o setor formal. Por fim, como os resultados mostraram, aparentemente o número de variáveis foi insuficiente para mostrar, com maior 
acurácia, mais fatores de diferenciação entre empresas que fecharam e que continuam em atividade.

Recomenda-se que este estudo seja ampliado com a aplicação de uma pesquisa longitudinal que considere o constructo desta para observar o comportamento de uma amostra dos empresários durante um período de cinco anos. É possível, também, ampliar o estudo para outros estados e incorporar informações sobre o setor informal.

\section{Referências}

ALDRICH, H.; ZIMMER, C. Entrepreneurship through social networks. In: SEXTON, D. L.; SMILER, R. W. (Eds.). Art and science of fintrepreneurship. Ballinger, 1987. p. 3-23.

ALMQUIST, E.; ANGUST, S. Role model influences on college women's career aspirations. Merrill-Palmer Quarterly of Behavior and Development, v. 17, n. 3, p. 263-279, 1971.

ANSOFF, H. l. Estratégia empresarial. São Paulo: McGraw-Hill,1989.

BATISTA, A. Estratégias de desenvolvimento e fatores críticos. Belo Horizonte: Fundação Dom Cabral; Programa de Desenvolvimento de Lideranças; Sistema SEBRAE, 2003.

BIRLEY, S.; MUZYKA, D. F. Dominando os desafios do empreendedor. São Paulo: Makron Books, 2001.

BRASIL. Ministério do Trabalho e Emprego. Relação Anual de Informações Sociais - RAIS. Brasília, DF, 2004.

BROLlO, M. X. Intenção empreendedora: um modelo econômicopsicológico entre estudantes universitários. 2005. $147 \mathrm{f}$. Tese (Doutorado em Engenharia de Produção)-Universidade Federal de Santa Catarina, Florianópolis, 2006.

CALOÊTE, E. M. F. Principais indicadores de número de estabelecimentos, ocupação da mão de obra e valor da massa salarial das empresas formalmente estabelecidas no Brasil 2003-2006. Disponivel em: <http://www.biblioteca.sebrae. com.br/>. Acesso em: 30 maio 2009.

CANTILLON, R. Essai sur la nature du commerce en général. Londres: Chez Fletcher Gyles dans Holborn, 1755.

CARSRUD, A. L.; GAGLIO, C. M.; KENNETH, W. 0. Entrepreneursmentors, networks and successful new venture development: an exploratory study. American Journal of Small Business, v. 12 , n. 2, p. 13-18, 1987.

GRECO, S. M. S. S. et al. Empreendedorismo no Brasil: 2008. Curitiba: IBQP, 2009.

HISRICH, R. D.; PETERS, M. Empreendedorismo. 5. ed. Porto Alegre: Bookman, 2004.
INSTITUTO BRASILEIRO DE GEOGRAFIA E ESTATÍSTICA - IBGE. Coordenação de Serviços e Comércio Il. Estudos e Pesquisas: Informação Econômica. Rio de Janeiro: IBGE, 2003. n. 1. (Série. As micro e pequenas empresas comerciais e de serviços no Brasil 2001).

INSTITUTO BRASILEIRO DE GEOGRAFIA E ESTATÍSTICA - IBGE. Demografia das empresas. 2005. Estudos e Pesquisas: Informação Econômica. Rio de Janeiro, 2007. v. 6.

LEZANA, A. G. R.; TONELLl, A. 0 comportamento do empreendedor. In.: DE MORI, F. Empreender: identificando, avaliando e planejando um novo negócio. Florianóplois: ENE, UFSC 1998.

LEZANA, A. G. R.; TONELLI, A. 0 comportamento do empreendedor. In.: DE MORI, F. (Org.). Empreender: identificando, avaliando e planejando um novo negócio. 2004. (Escola de Novos Empreendedores).

LONGENECKER, J. G.; MOORE, C. W.; PETTY, J. W. Administração de pequenas empresas. São Paulo: Makron Books, 2004.

MOREIRA, S. Por um modelo catarinense de desenvolvimento para $o$ século XXI. PNUD - Programa das Nações Unidas para o Desenvolvimento, 2005.

OLIVEIRA, J. Empreendedorismo no âmbito da administração pública. Líder de Bandeirantes, 24 mar. 2005.

ORTIGARA, A. A. Causas que condicionam a mortalidade e/ou sucesso das micro e pequenas empresas no estado de Santa Catarina. 2006. 173 f. Tese (Doutorado em Engenharia de Produção) Universidade Federal de Santa Catarina, Florianópolis, 2006.

SCHLEMM, M. M. et al. Empreendedorismo no Brasil: 2006. Curitiba: IBQP, 2007.

SCHUMPETER, J. A. The theory of economic development. New York: Oxford University Press, 1961.

SCOTT, M.; BRUCE, R. Five stages of growth in small business. Long Range Planning, v. 20, n. 3, p.45-52, 1987.

SEBRAE. Fatores condicionantes e taxa de mortalidade de empresas no Brasil. Relatório de pesquisa. Brasília, 2004.

SHANE, S.; LOCKE, E.; COLLINS, C. J. Entrepreneurial motivation. Human Resource Management Review, v. 13, n. 2, p. 257-279, 2003.

SMAKE, J. E.; GRANGER, C. R. Same-sex and opposite-sex teacher model influences on science career commitment among high school students. Journal of Educational Psychology, v. 70, n. 2, p. 180-186, 1978.

STEEL, R. G. D.; TORRIE, J. H. Bioestatística: princípios e procedimientos. 2. ed. México: McGraw Hill, 1988.

STEL, A. V.; CARREE, M.; THURIK, R. The effect of entrepreneurial activity on national economic growth. Small Business Economics, v. 24, p.311-321, 2005.

\title{
Factors affecting the success and/or the mortality of micro and small companies in Santa Catarina
}

\begin{abstract}
The article's objective is to describe which factors affecting to the success and/or the mortality of micro and small companies in the State of Santa Catarina are. It was elaborated, therefore, a field study with a sample of companies registered on Junta Comercial do Estado de SC from 2000 to 2004. The data were analyzed in quality and quantity method under two perspectives: i) Relevant factors on enterprise's history (real), which highest averages grades were given to the product/market knowledge, business focus, identification of opportunities, organization and product' suitability; and ii) factors that the entrepeneur believes to be the most important for the success (ideal), which highest averages grades were given to the organization, the relationship among the partners, the knowledge about the market, the business focus and the identification of oportunities.
\end{abstract}

Keywords

Success. Failure. Factors affecting. Micro and small companies. 